\title{
Vivax malaria and chloroquine resistance: a neglected disease as an emerging threat
}

\author{
Anam A Waheed ${ }^{1}$, Najia K Ghanchi ${ }^{2}$, Karim A Rehman', Afsheen Raza ${ }^{2}$, Syed F Mahmood ${ }^{3}$ and Mohammad A Beg ${ }^{2 *}$
}

\begin{abstract}
In Pakistan, Plasmodium vivax contributes to major malaria burden. In this case, a pregnant woman presented with $P$. vivax infection and which was not cleared by chloroquine, despite adequate treatment. This is probably the first confirmed case of chloroquine-resistant vivax from Pakistan, where severe malaria due to $P$. vivax is already an emerging problem.
\end{abstract}

Keywords: Malaria, Chloroquine resistance, Artemisinin combination therapy

\section{Background}

Plasmodium vivax malaria continues to be a global threat, affecting 2.8 million people [1]. Chloroquine (CQ) has remained the first-line of treatment for $P$. vivax since the 1940s [2] and seemed to be universally effective until the first case of CQ-resistant $P$. vivax was reported from Papua New Guinea [3]. There have been some reports of CQ resistance across the globe [4] but CQ remains the mainstay of treatment in most regions. This study probably reports the first case of CQresistant $P$. vivax found in Karachi, Pakistan.

\section{Patient}

A 26 years old female presented at 34 weeks of gestation to the labour room at Aga Khan University Hospital (AKUH) with a three-day history of fever. The patient had been experiencing high grade fever for the past three days, associated with chills and rigours, as well as anorexia, malaise, myalgia, and back pain. These complaints had prompted her to go to Civil Hospital Karachi where a Giemsa-stained peripheral smear had shown $P$. vivax. She had then elected to come to AKUH for treatment.

\section{Clinical findings}

On examination, she was alert and oriented to time place and person. Vital signs showed her to be febrile

\footnotetext{
* Correspondence: masim.beg@aku.edu

${ }^{2}$ Department of Pathology and Laboratory Medicine, Aga Khan University, Stadium Road, PO Box 3500, Karachi 74800, Pakistan

Full list of author information is available at the end of the article
}

with a temperature elevation of $38^{\circ} \mathrm{C}$ and tachycardia with a heart rate of 140 beats/min. Her blood pressure was $100 / 70 \mathrm{mmHg}$, respiratory rate of 14 . She was saturating $99 \%$ on room air. Respiratory examination was unremarkable with normal vesicular breathing bilaterally. Cardiac examination was normal. Abdominal examination showed a fundal height of $34 \mathrm{~cm}$, with a longitudinal lie, cephalic presentation, and audible foetal heart sounds.

Laboratory investigations prior to admission showed haemoglobin of $10.0 \mathrm{~g} / \mathrm{dL}$, a platelet count of $285,000 / \mathrm{mm}^{3}$, white blood cell (WBC) count of $4.6 \times 10^{3}$. Thick and thin blood films were positive for $P$. vivax mono-infection. Dengue IgM and IgG were negative. Laboratory finding on day of admission showed haemoglobin of $9.6 \mathrm{mg} / \mathrm{dL}$, a platelet count of 57,000 . WBC count was $3.6 \times 10^{3}$, with a differential of $90 \%$ neutrophils and $8 \%$ lymphocytes. Coagulation profile (prothrombin time, activated partial tissue thromboplastin time) was also normal. Electrolytes revealed sodium $=133 \mathrm{mmol} / \mathrm{L}$, potassium $=3.3 \mathrm{mmol} / \mathrm{L}$, chloride $=107 \mathrm{mmol} / \mathrm{L}$, bicarbonate $=13.2 \mathrm{mmol} / \mathrm{L}$, and a random glucose $=116 \mathrm{mg} / \mathrm{dL}$. Liver function tests were within normal ranges. Urinalysis revealed trace proteinuria and haemoglobinuria. Chest X-ray was normal and foetal cardiograph was reactive.

Microscopic examination of Giemsa-stained blood smear showed trophozoites of $P$. vivax. Rapid diagnostic testing using a Plasmodium falciparum/P. vivax antigen detection kit (ICT Detection Kit, Sydney, Australia) revealed a $P$. vivax infection. 
The patient was admitted and started on CQ regimen, $1,000 \mathrm{mg}$ given immediately followed by $500 \mathrm{mg}$ after six hours and $500 \mathrm{mg}$ for the next two days. She was also given acetaminophen $1,000 \mathrm{mg}$ for her fever and ferrous sulphate and calcium tablets were continued. She was monitored clinically and microscopy performed six hourly. For the next three days, she continued to spike fevers on the full CQ regimens and blood films remain positive for malarial parasite. Her haemoglobin decreased progressively over the next three days to $8.0 \mathrm{mg} / \mathrm{dL}$ and her platelet count continued to drop to $48,000 / \mathrm{mm}^{3}$.

She was monitored intensively, with bleeding precautions initiated and the Infectious Diseases' team was consulted. When she failed to defervesce for greater than 12 hours for three consecutive days and remained positive for Plasmodium on Giemsa smears, her regimen was changed to a combination therapy of artemether and lumefantrine $(40 \mathrm{mg} / 240 \mathrm{mg}$ ). This is a three-day treatment schedule with one dose given immediately, another dose after eight hours and then subsequent doses at 24 and 36 hours. On initiation of this regimen, the patient defervesced rapidly, and remained afebrile. Subsequent Giemsa smears also revealed absence of parasitaemia, and $P$. vivax infection was successfully cleared.

On follow-up, there was no relapse of malaria, and the patient delivered a healthy baby through spontaneous vaginal delivery without any complications.

\section{Molecular analysis}

Plasmodium vivax mono-infection was confirmed on microscopy, immuno-chromatography test (ICT) and polymerase chain reaction. Genotyping analysis revealed that the sample carried pvmsp-1 Type 1 and pvcsp VK 210 repeat types. Furthermore, analysis of sulphadoxinepyrimethamine (SP) resistance associated mutations in pvdhfr and pvdhps genes showed presence of 117 N, 50 I and $119 \mathrm{~K}$ mutations. Both $117 \mathrm{~N}$ and 50I mutation have been associated with emerging resistance against SP, implying that the patient was infected with SP-resistant strain of $P$. vivax. Interestingly, no mutation was observed in the pvcrt-o gene, however, the possibility of $P$. vivax strain accumulating mutations in other CQ-binding regions cannot be ruled out in this study. Lack of validated molecular markers to monitor CQ resistance is a major limitation in surveillance of resistant strains of $P$. vivax globally. With regard to cytokine levels, TNF, IL-10 and ICAM-1 concentrations were found to be raised, indicating that respective cytokines and endothelial markers were upregulated in response to treatment failure, and may have led to further inflammation via parasite exposure.

\section{Discussion}

Some 2.8 billion people across the globe are at risk of infection by $P$. vivax [1] and estimates of the total annual number of cases range between 70 and 390 million people $[5,6]$. These figures are suspected to be underestimates of the true burden of disease because of limitations in the coverage for malaria notification and diagnosis in many endemic areas [7]. There has been a recent increase in the severity and morbidity of malaria caused by $P$. vivax and it is speculated to be associated with infection with drug resistant strains of $P$. vivax [6]. There are reports documenting mutations predisposing to CQ resistance present in $P$. vivax strains [8]. This portends serious consequences for public health and global burden of disease if CQ-resistant strains become widespread.

Malaria remains an endemic disease in Pakistan with an estimated health care burden of 1.6 million cases annually [9]. Plasmodium falciparum and P. vivax have been the species documented to be responsible for this, with $P$. vivax accounting for $67 \%$ of reported cases. In a developing country where people struggle to afford mainstream antimalarial medication, the possible appearance and spread of CQ-resistant P. vivax is cause for alarm. It would place a huge burden on an already strained healthcare system, and morbidity and mortality due to malaria would increase.

Resistance to CQ has been defined as parasitaemia detectable at 72 hours after initiation of therapy, or reappearance of parasitaemia within 28 days in spite of CQ levels being maintained above $100 \mathrm{ng} / \mathrm{ml}$ [10]. In this patient, parasitaemia was detectable while being on the full therapeutic regimen, hence falling into the category of CQ resistance and treatment failure. However, the absence of serum concentration of CQ or desethylchloroquine which is required to confirm the adequate absorption of the drug is a limitation of this study.

Molecular genetic studies have revealed that $P$. vivax from areas with a high incidence of CQ resistance carry single nucleotide polymorphisms in the multidrug resistance gene (pmvdr1) [11]. Multiple studies have documented mutations in the pvcrt-o gene to be associated with tolerance to CQ [12]. Genotypic variations in P. vivax dihydrofolate reducatase gene ( $p v d h f r)$ as well as $P$. vivax dihyropteroate synthetase ( $p v d h p s)$ have also been implicated in drug resistance [8], including in isolates from Pakistan [13].

CQ resistance has not been reported previously from Pakistan. However, a recent study carried out molecular genetic analysis of strains of $P$. vivax from Pakistan, sequencing $p v d h f r, p v d h p s$ and $p m v d r 1$, which are associated with CQ resistance $[14,15]$. It reports a high prevalence of $P$. vivax mutant pvmdr1 mutant codon F1076L, which points towards the possibility of the efficacy of CQ plus primaquine being compromised in future, but no clinical correlation has been made [16].

\section{Conclusion}

It is suggested the possible presence of CQ-resistant $P$. vivax strains in Pakistan and may be an emerging 
threat. Clinicians need to be aware that patients failing treatment may be infected with CQ-resistant P. vivax strains. In settings where resources allow, these strains can be analysed with molecular and immunological markers so that the extent and impact of drug pressure may be monitored effectively.

\section{Consent}

Written informed consent was obtained from the patient for the publication of this report and any accompanying images.

\section{Competing interests}

The authors declare that they have no competing interests.

\section{Authors' contributions}

$M A B, S F M$ and $A A W$ were responsible for clinical work, designed and planned the study. NKG, AR and KAR performed microscopy, PCR genotyping, ELISA analysis, and interpretation. AAW and NKG prepared the initial manuscript. $M A B$ reviewed the final draft. All authors read and approved the final manuscript.

\section{Acknowledgements}

All molecular studies for this project were funded by an Aga Khan University Research Council grant.

\section{Author details}

${ }^{1}$ Medical College, Aga Khan University, Karachi, Pakistan. ${ }^{2}$ Department of Pathology and Laboratory Medicine, Aga Khan University, Stadium Road, PO Box 3500, Karachi 74800, Pakistan. ${ }^{3}$ Section of Adult Infectious Diseases, Department of Medicine, Aga Khan University, Stadium Road, PO Box 3500, Karachi 74800, Pakistan.

Received: 19 December 2014 Accepted: 20 March 2015

Published online: 08 April 2015

\section{References}

1. Guerra CA, Howes RE, Patil AP, Gething PW, Van Boeckel TP, Temperley WH, et al. The international limits and population at risk of Plasmodium vivax transmission in 2009. PLoS Negl Trop Dis. 2009:4:e774.

2. Baird JK. Chloroquine resistance in Plasmodium vivax. Antimicrob Agents Chemother. 2004;48:4075-83.

3. Rieckmann $\mathrm{KH}$, Davis DR, Hutton DC. Plasmodium vivax resistance to chloroquine? Lancet. 1989;2:1183-4.

4. Price RN, von Seidlein L, Valecha N, Nosten F, Baird JK, White NJ. Global extent of chloroquine-resistant Plasmodium vivax: a systematic review and meta-analysis. Lancet Infect Dis. 2014;14:982-91.

5. Hay SI, Guerra CA, Tatem AJ, Noor AM, Snow RW. The global distribution and population at risk of malaria: past, present, and future. Lancet Infect Dis. 2004:4:327-36.

6. Price RN, Tjitra E, Guerra CA, Yeung S, White NJ, Anstey NM. Vivax malaria: neglected and not benign. Am J Trop Med Hyg. 2007;77:79-87.

7. Goncalves LA, Cravo P, Ferreira MU. Emerging Plasmodium vivax resistance to chloroquine in South America: an overview. Mem Inst Oswaldo Cruz. 2014;109:53

8. Garg S, Saxena V, Lumb V, Pakalapati D, Boopathi PA, Subudhi AK, et al. Novel mutations in the antifolate drug resistance marker genes among Plasmodium vivax isolates exhibiting severe manifestations. Exp Parasitol. 2012;132:410-6

9. WHO. World malaria report 2012. Geneva: World Health Organization; 2012

10. Baird JK, Sustriayu Nalim MF, Basri H, Masbar S, Leksana B, Tjitra E, et al. Survey of resistance to chloroquine by Plasmodium vivax in Indonesia. Trans R Soc Trop Med Hyg. 1996;90:409-11.

11. Suwanarusk R, Russell B, Chavchich M, Chalfein F, Kenangalem E, Kosaisavee V, et al. Chloroquine resistant Plasmodium vivax: in vitro characterization and association with molecular polymorphisms. PLoS One. 2007;2:e1089.

12. Sa JM, Yamamoto MM, Fernandez-Becerra C, de Azevedo MF, Papakrivos J, Naude B, et al. Expression and function of pvcrt-o, a Plasmodium vivax ortholog of pfcrt, in Plasmodium falciparum and Dictyostelium discoideum. Mol Biochem Parasitol. 2006:150:219-28.

13. Raza A, Ghanchi NK, Khan MS, Beg MA. Prevalence of drug resistance associated mutations in Plasmodium vivax against sulphadoxinepyrimethamine in southern Pakistan. Malar J. 2013;12:261.

14. Hawkins VN, Joshi $\mathrm{H}$, Rungsihirunrat $\mathrm{K}$, Na-Bangchang $\mathrm{K}$, Sibley $\mathrm{CH}$ Antifolates can have a role in the treatment of Plasmodium vivax. Trends Parasitol. 2007;23:213-22.

15. Hastings MD, Maguire JD, Bangs MJ, Zimmerman PA, Reeder JC, Baird JK, et al. Novel Plasmodium vivax dhfr alleles from the Indonesian Archipelago and Papua New Guinea: association with pyrimethamine resistance determined by a Saccharomyces cerevisiae expression system. Antimicrob Agents Chemother. 2005;49:733-40.

16. Khattak AA, Venkatesan M, Khatoon L, Ouattara A, Kenefic L, Nadeem MF, et al. Prevalence and patterns of antifolate and chloroquine drug resistance markers in Plasmodium vivax across Pakistan. Malar J. 2013;12:310.

\section{Submit your next manuscript to BioMed Central and take full advantage of:}

- Convenient online submission

- Thorough peer review

- No space constraints or color figure charges

- Immediate publication on acceptance

- Inclusion in PubMed, CAS, Scopus and Google Scholar

- Research which is freely available for redistribution 